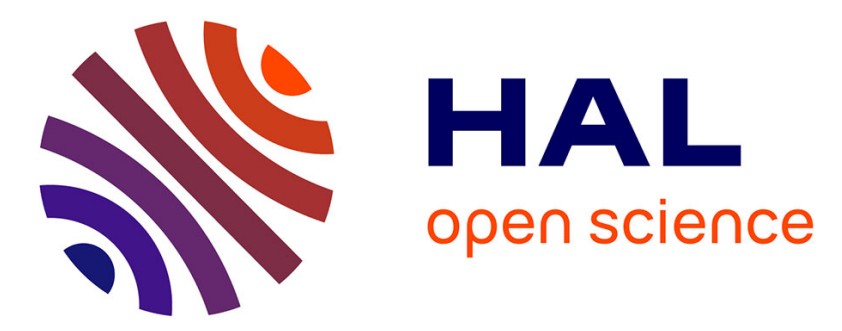

\title{
Links between mechanical behavior of cancellous bone and its microstructural properties under dynamic loading
}

Marianne Prot, Dominique Saletti, Stéphane Pattofatto, Valérie Bousson, Sébastien Laporte

\section{To cite this version:}

Marianne Prot, Dominique Saletti, Stéphane Pattofatto, Valérie Bousson, Sébastien Laporte. Links between mechanical behavior of cancellous bone and its microstructural properties under dynamic loading. Journal of Biomechanics, 2015, 48 (3), pp.498-503. 10.1016/j.jbiomech.2014.12.002 . hal02447054

\section{HAL Id: hal-02447054 \\ https://hal.science/hal-02447054}

Submitted on 17 Sep 2020

HAL is a multi-disciplinary open access archive for the deposit and dissemination of scientific research documents, whether they are published or not. The documents may come from teaching and research institutions in France or abroad, or from public or private research centers.
L'archive ouverte pluridisciplinaire HAL, est destinée au dépôt et à la diffusion de documents scientifiques de niveau recherche, publiés ou non, émanant des établissements d'enseignement et de recherche français ou étrangers, des laboratoires publics ou privés. 


\title{
Links between mechanical behavior of cancellous bone and its microstructural properties under dynamic loading
}

\author{
M. Prot ${ }^{\mathrm{a}, *}$, D. Saletti ${ }^{\mathrm{a}, \mathrm{b}}$, S. Pattofatto ${ }^{\mathrm{c}}$, V. Bousson ${ }^{\mathrm{d}}$, S. Laporte ${ }^{\mathrm{a}}$ \\ a LBM/Institut de Biomécanique Humaine Georges Charpak, 151 Boulevard de l'Hôpital, 75013 Paris, France \\ ${ }^{\mathrm{b}}$ Univ. Grenoble Alpes, 3SR, F-38000 Grenoble, France \\ ' LMT-Cachan (ENS Cachan/CNRS/Université Paris VI/Pres UniversSud Paris), 61 Avenue du Président Wilson, 94230 Cachan, France \\ d Service de Radiologie Ostéo-Articulaire, Hôpital Lariboisière, Paris, France
}

Keywords:

Cancellous bone

Microstructural parameters

Dynamic behavior

Confinement

\begin{abstract}
A B S T R A C T
Previous studies show that in vivo assessment of fracture risk can be achieved by identifying the relationships between microarchitecture description from clinical imaging and mechanical properties. This study demonstrates that results obtained at low strain rates can be extrapolated to loadings with an order of magnitude similar to trauma such as car crashes. Cancellous bovine bone specimens were compressed under dynamic loadings (with and without confinement) and the mechanical response properties were identified, such as Young's modulus, ultimate stress, ultimate strain, and ultimate strain energy. Specimens were previously scanned with pQCT, and architectural and structural microstructure properties were identified, such as parameters of geometry, topology, connectivity and anisotropy. The usefulness of micro-architecture description studied was in agreement with statistics laws. Finally, the differences between dynamic confined and non-confined tests were assessed by the bone marrow influence and the cancellous bone response to different boundary conditions. Results indicate that architectural parameters, such as the bone volume fraction (BV/TV), are as strong determinants of mechanical response parameters as ultimate stress at high strain rates ( $p$-value $<0.001$ ). This study reveals that cancellous bone response at high strain rates, under different boundary conditions, can be predicted from the architectural parameters, and that these relations with mechanical properties can be used to make fracture risk prediction at a determined magnitude.
\end{abstract}

\section{Introduction}

Cancellous bone has a porous structure that protects the marrow contained in the cortical bone layer. A better understanding of bone fracture is necessary to improve the musculoskeletal modeling of the human body intended to aid in the design of protective features. The mechanical properties of cancellous bone, over a large range of strain rates, have been studied to better simulate and understand injuries sustained such as during a car crash (Chaary et al., 2007). Researchers have made great progress in characterizing the compressive behavior on cases of quasi-static loading (Guedes et al., 2006), and recently accounting for the influence of bone marrow (Halgrin et al., 2012; Charlebois et al., 2008). The few experimental studies entailing mechanical characterization at high strain rates have proved that the mechanical behavior is strain rate dependent (Linde et al., 1991). Furthermore, as cancellous bone is highly heterogeneous with a variation depending, among others, on age (Follet et al., 2011), anatomic localization (Morgan and Keaveny, 2001), and geometry

\footnotetext{
* Corresponding author. Tel.: +33 144246364; fax: + 33144246366.
}

E-mail address: marianne.prot@ensam.eu (M. Prot).
(Linde et al., 1992), studies have recently demonstrated that the characterization of cancellous bone architecture was a good predictor of low strain rate mechanical response (Zhou et al., 2014). Given the daily life loadings, it would be interesting to characterize the dynamic response of cancellous bone in regards to its architectural description. However, there is a lack of this in the literature.

The aim of this study is to quantify the links between architectural descriptors of cancellous bone and macroscopic mechanical behavior under high strain rate compression loading for two boundary conditions.

\section{Materials and Methods}

\subsection{Samples}

Twenty-four distal segments of 3 years old bovine femoral bones were used for this study ( $72 \mathrm{~h}$ post-mortem) and frozen at $-20{ }^{\circ} \mathrm{C}$ ( Linde and Sørensen, 1993). Experiments were conducted within the animal welfare regulations and guidelines for the country. A diamond slitting wheel was used to isolate two cylinders of cancellous bone from each frozen bone in the sagittal plane (diameter $41 \mathrm{~mm}$ and thickness $14 \mathrm{~mm}$ ). Specimens were then preserved in vacuum-sealed plastic bags; they were slowly thawed for $12 \mathrm{~h}$ at $+5{ }^{\circ} \mathrm{C}$ before being exposed to room temperature (approximately $+24^{\circ} \mathrm{C}$ ) prior to mechanical testing (Mitton et al., 1997). 


\section{Results}

The peripheral quantitative tomodensitometry technique (pQCT) was used to identify the microstructure properties of each frozen cylinder (XtremeCT, Scanco Medical, cubic voxel size: $42 \mu \mathrm{m}$ ( $<80 \mu \mathrm{m}$ (Van Rietbergen et al., 1995), X-ray tube potential (peak): $60 \mathrm{kVp}$, Integration time: $1680 \mathrm{~ms}$ per slice (Bouxsein et al., 2010) with a low dose of radiation (Genant et al., 1996). According to the literature (Follet et al., 2005; Syahrom 2011; Yeni et al., 2011, Garrison et al., 2011; Nazarian et al., 2011), 14 architectural parameters of cancellous bones were selected and computed using BoneJ (Doube et al., 2010) from the DICOM files. Parameters were divided into four groups: architectural descriptors of geometry, topology, connectivity and anisotropy. Parameters, units, and groups are presented in Table 1.

\subsection{Experimental technique and mechanical properties}

Experiments were performed as described in a previous study (Laporte et al. 2009). Twenty-four specimens underwent dynamic loading using a Split Hopkinson nylon Pressure Bar system (Liu et al., 2014) (SHPB, Fig. 1). A SHPB system operates under the following principles: a striker first impacts the free end of the input bar; this impact generates a compressive wave, known as the incident wave which propagates through the input bar. When it reaches the input bar-specimen interface, part of the wave is reflected back along the input bar as a tensile wave, referred to as the reflected wave. The remaining part of the wave is transmitted, through the specimen to the output bar and is known as the transmitted wave. The relative magnitudes of the waves, registered through gages, relate to the materia properties of the specimen at high strain rate. The data analysis for the SHPB tests was conducted using the DAVID software (Gary, 2005).

Samples were divided for two tests series with different applied boundary conditions: typical compression tests without confinement for 12 specimens (D, ca $1000 \mathrm{~s}^{-1}$ ) and confined dynamic tests for the 12 remaining specimens (CD, $\mathrm{ca}$ $1500 \mathrm{~s}^{-1}$ ). For the latter, bone was placed in an aluminum confined cell (Fig. 2, inner diameter: $41 \mathrm{~mm}$, i.e., the bars diameter, to only test the bone). Dimensions were chosen to limit the radial expansion of the structure and the flow of bone marrow. Then a compromise has been made in order to keep the specimen free of internal stresses and directly in contact with the cell, in order to be close to in-vivo boundary condition with cortical bone.

The mechanical properties were identified by an automatic process: ultimate stress and strain were determined at the maximum value of stress history (see Fig. 3 left) while the apparent Young's modulus was calculated based on the gradient of the stress versus. strain graph for the middle one third of the strain range between zero and ultimate strain (see Fig. 3 right). Initial strain was set as the left-shifting of the stress-strain curve based on the linear extrapolation to zero stress (Boruah et al., 2013).

\subsection{Data analysis}

Kruskal-Wallis test was used to determine if there is a difference between the 2 groups of micro-architectural parameters. Mann-Whitney statistical test (nonparametric hypothesis test) was performed for mechanical parameters to appraise the influence of boundary conditions. After validating the previous studies, the Spearman statistical test (non-parametric one-way analysis of variance by ranks) was used to highlight correlations between architectural and mechanical parameters. A $p$-value of 0.05 was chosen as the upper threshold of significance. All statistical tests were performed using XLSTAT.

\subsection{Microstructure and mechanical properties}

To perform the analysis study, the variability of experimental and architectural data had been investigated. An illustration is presented in Fig. 4. This representation allows exploring the dataset mean (illustrated with a cross), the median (straight line), the 1st quartile and the 3rd quartile (ends of the box), the highest and lowest values (ends of the whiskers) and outliers if any (individual points). Medians, interquartile ranges, extremes values, mean values and standard deviations of all microstructure parameters for the loaded specimens are given in Table 2. Values for each specimen are tabulated in Supplementary information. Architectural parameters were consistent between the two sets of testing groups (minimum $p$-value for Kruskal-Wallis test: 0.44 ).

Architectural values have been found relevant to the literature dedicated to bovine samples (Syahrom, 2011; Halgrin, 2009; Garrison et al., 2011).

The two different groups can be compared as the maximum $p$ value is 0.006 for the Mann-Whitney test.

Descriptive statistics of mechanical parameters for the 24 compressed specimens are provided in Table 2. Supplementary information provides the actual test data for all the loaded specimens. Data published for bovine cancellous bone loaded to high strain rates (Higgins, 2008; Halgrin, 2009) set the same magnitude of individual variation.

As no work had been reported regarding confined dynamic loading, no comparison can be made; however, the confinements lead to a temperature elevation and added to the marrow influence. It appears that both apparent Young's modulus and ultimate stress increase in regard to non-confined testing (Halgrin, 2009).

\subsection{Links between mechanical and microstructural parameters}

As mentioned above, it is well known that mechanical response is linked to architecture. A bone presenting a higher bone

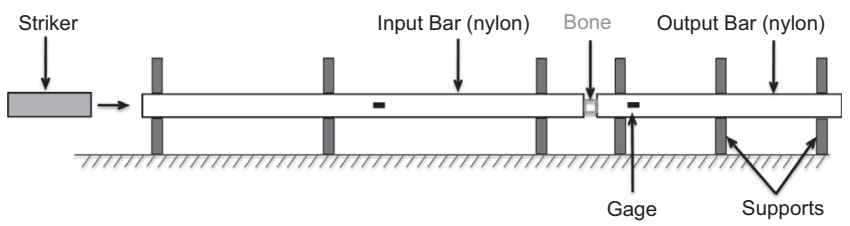

Fig. 1. Split Hopkinson Pressure Bar system used for high strain rate compressive testing.

Table 1

Summary of architectural parameters.

\begin{tabular}{|c|c|c|c|}
\hline Family & Parameter & Description & Unit \\
\hline \multirow[t]{6}{*}{ Geometry and morphology } & BS & Bone surface & $\mathrm{mm}^{2}$ \\
\hline & BV & Bone volume & $\mathrm{mm}^{3}$ \\
\hline & $\mathrm{BV} / \mathrm{TV}$ & Bone volume/total volume & $\%$ \\
\hline & Tb.Th & Mean thickness of trabeculae & $\mathrm{mm}$ \\
\hline & Tb.Sp & Trabecular separation & $\mathrm{mm}$ \\
\hline & Conn.D & Connectivity density or number of trabeculae per unit volume & $/ \mathrm{mm}^{3}$ \\
\hline \multirow[t]{2}{*}{ Topology } & FD & Fractal dimension & \\
\hline & SMI & Structure model index & \\
\hline \multirow[t]{6}{*}{ Connectivity } & Nd.Nd & Average branch length & $/ \mathrm{mm}^{3}$ \\
\hline & N.Nd & Number of junctions & $/ \mathrm{mm}^{3}$ \\
\hline & N.Jnv & Number of junction voxel, i.e. number of voxels labeled as being in a junction with more than 2 neighbors & $/ \mathrm{mm}^{3}$ \\
\hline & N.Slv & Number of slab voxel, i.e. number of voxels labeled as being in a junction with 2 neighbors & $/ \mathrm{mm}^{3}$ \\
\hline & N.Tp & Number of triple point, i.e. number of junctions with 3 branches & $/ \mathrm{mm}^{3}$ \\
\hline & N.Qp & Number of quadruple point, i.e. number of junctions 4 branches & $/ \mathrm{mm}^{3}$ \\
\hline \multirow[t]{2}{*}{ Anisotropy } & $\mathrm{DA}$ & Degree of anisotropy & \\
\hline & MIL & Mean intercept length & $\mathrm{mm}$ \\
\hline
\end{tabular}



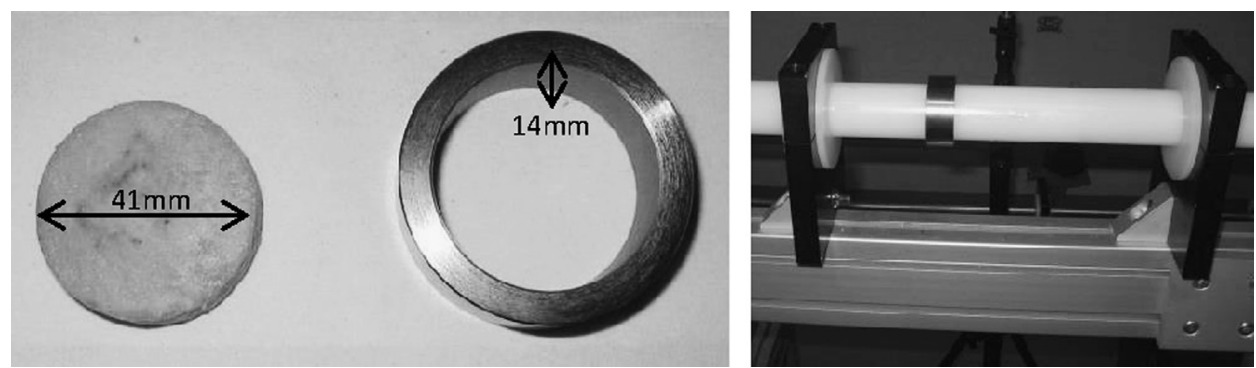

Fig. 2. Confined cell and its setup on the Split Hopkinson Pressure Bar system.
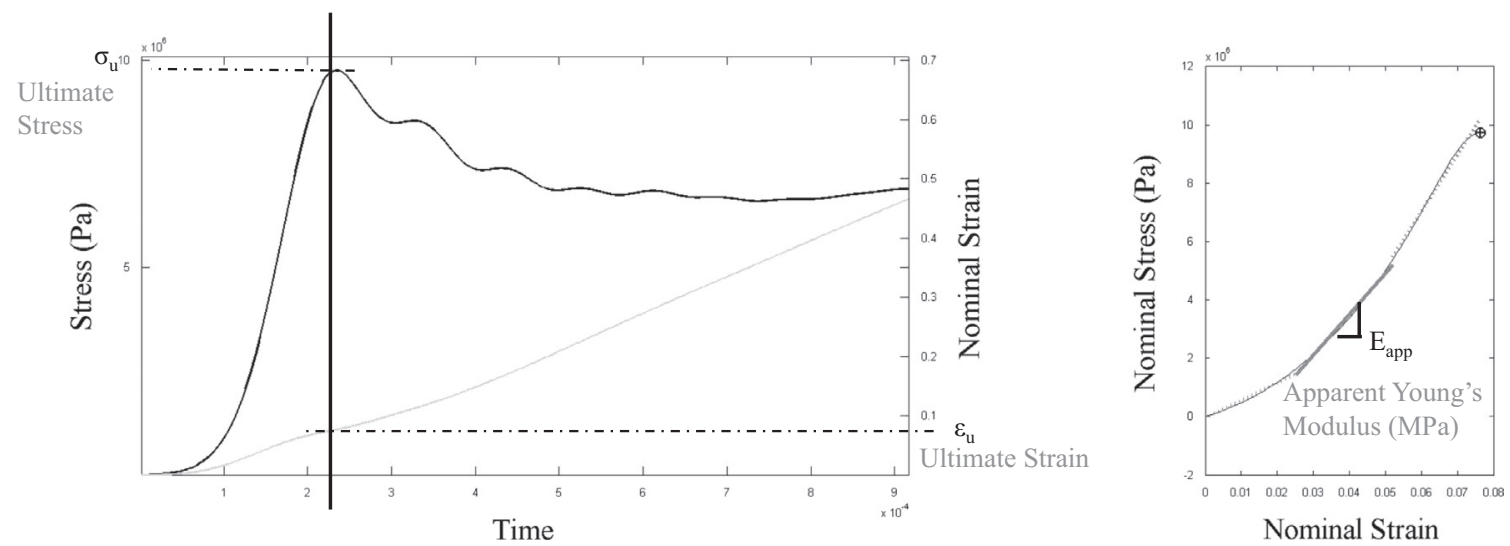

Fig. 3. Mechanical response parameters in the stress-strain curve.

$\mathrm{BV} / \mathrm{TV}$

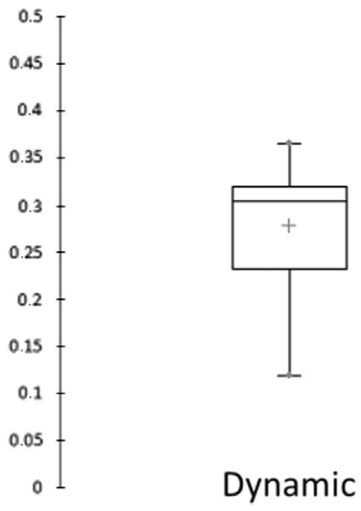

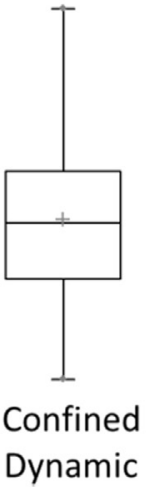

Ultimate Stress

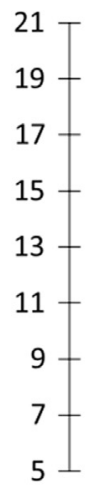

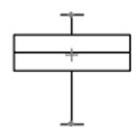

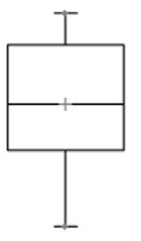

Dynamic

\section{Confined}

Dynamic

Fig. 4. Bone volume fraction $B V / T V$ and ultimate stress repartition: box and whiskers plot.

volume fraction will have more materials to answer the mechanical loading and will then present a higher ultimate stress. All trend lines between mechanical properties evolution and architectural parameters had been checked, and an overview of the data repartition is presented in Fig. 5.

Similar trends were observed for both dynamics loadings. There is a persistent correlation between $E_{\text {app }}$ and the three MIL parameters at different strain rates.

Results of Spearman's correlation tests are reported in Table 3. Mechanical properties identified under dynamic loading can be predicted by microstructural parameters except by N.Jn $n_{v}$ (number of junction voxel) and DA (degree of anisotropy). Persistent correlations were observed for both boundary conditions, such as Young's modulus versus the 3 different MIL, BV/TV and Tb.Sp. $\varepsilon_{\mathrm{u}}$ presents no correlations for dynamic loading such as $\sigma_{\mathrm{u}}$ for the confined dynamic loading.

\section{Discussion}

\subsection{Links between mechanical and microstructural parameters}

As several studies had been reported in the case of quasi-static non-confined loading, it appears relevant to check the correlation consistency with the strain rate. In Table 4, an overview of the pertinent published data is compared to the non-confined dynamic study presented in this article.

Similar correlations with geometry (BV/TV, Tb.Th, Tb.Sp) and anisotropy parameters (the three MIL) were identified with regard to $E_{\text {app }}$ for both strain rate loadings. The absence of correlation with DA was also found in previous work (Mittra et al., 2005; Teo et al., 2006) such as the Conn.D. The two references highlighted in Table 4 permit confirmation that $\varepsilon_{\mathrm{u}}$ is unrelated to architectural parameters. 


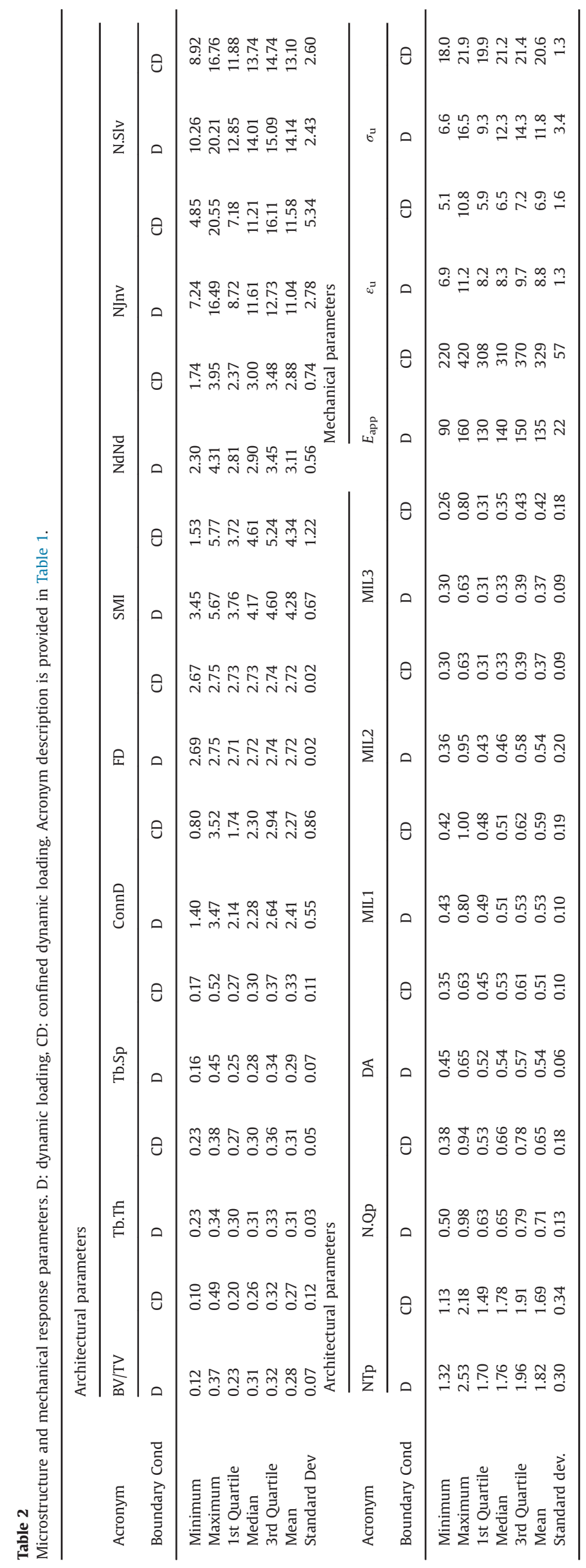

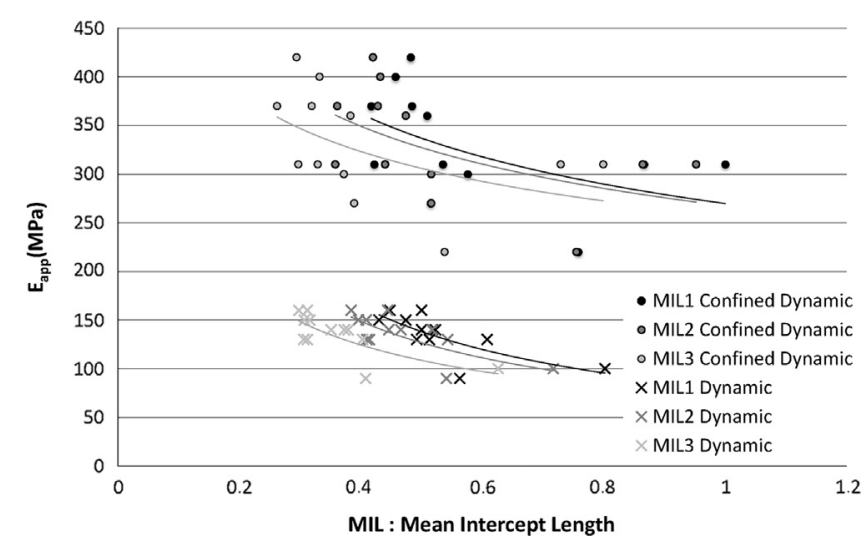

Fig. 5. Regressions for correlated parameters MIL1, MIL2 and MIL3 and Eapp: power law.

The correlations highlighted are correct in the studied range of values and can be carefully extrapolated to bigger intervals. Fig. 6 illustrates the difference of variation range with Perilli et al. (2007). Power trend lines appear to be really similar but the amplitude effect is noticeable. Due to this combination with the strain rate effect between this dynamic study and the quasi-static reference (Perilli et al., 2007), this effect was not quantified.

The reference studies reveal a connection between Tb.Th and the ultimate stress and between SMI and the apparent Young's modulus that the present study did not confirm. The small amplitude of architectural parameters distribution (Tb.Th varying from 0.23 to 0.34 ) can explain the lack of correlation. Furthermore, the $p$-value associated with the correlation between Tb.Th and the ultimate stress of the dynamic study (Halgrin, 2009) is weak: $p$-value of 0.04. The amplitude of the architectural parameters distribution is specimen dependent. Then the absence of correlation between Conn.D and $\varepsilon_{\mathrm{u}}$ needs to be carefully considered and is only trustworthy in the studied range.

Architectural parameters outliers were considered for the correlation study as, in most part, they did not interfere with it. If it is true that outliers drive correlation, the difference between the Spearman $p$-values with outlier and without outliers is low. For Tb.Sp correlation with $E_{\text {app }}$ under confined dynamic loading, $p$ value is 0.028 with the outlier point and 0.025 without. Low $p$ value differences were observed for dynamic loading with $\mathrm{N}^{-S l_{v}}$, DA, MIL1 and MIl2 and for confined dynamic loading with FD, MIL1 and MIL3 and did not affect the correlation assessment. In fact, individually, architectural parameters can present outlier. It usually appears that the mechanical parameter outlier is obtained from the same sample and does not affect the correlation.

Only two correlations were affected by removing the outliers (illustrated in Table 3). Conn.D correlation was changed: $p$-value increased to 0.058 for its correlation with ultimate stress under confined dynamic loading. This correlation disappearance with a $p$-value close to the upper threshold of significance, correlation evidence is highly linked to the choice of this level. The second change was observed for MIL3 and $E_{\text {app }}$ ( $p$-value up to 0.095 without outliers). In this special case, both outliers were not linked and leads to a data loss of $17 \%$. Such a decrease in the amount of values may affect the consistency of the statistical analysis.

A set of architectural parameters can lead to different macroscopic arrangements of trabeculae. This can result in a mechanical difference. An investigation on that variability added to a study of architectural parameters sensitivity may significantly inform on the prediction of cancellous bone response to compression loading, and explain that quasi-static references and dynamic ones present disagreement for $\sigma_{\mathrm{u}}$, such as the Tb.Sp and the degree of anisotropy. 
Table 3

Spearman's tests results considering outliers.

\begin{tabular}{|c|c|c|c|c|c|c|c|c|c|c|c|c|c|c|c|c|c|}
\hline & & $\mathrm{BV} / \mathrm{TV}$ & Tb.Th & Tb.Sp & Conn.D & FD & SMI & Nd.Nd & N.Nd & N.Jnv & N.Slv & N.Tp & N.Qp & DA & MIL1 & MIL2 & MIL3 \\
\hline$E_{\text {app }}$ & Dynamic & $*$ & $*$ & $*$ & & $*$ & & & $*$ & & $*$ & $*$ & $*$ & & $* *$ & $*$ & $*(\mathrm{AO})$ \\
\hline$\varepsilon_{\mathrm{u}}$ & $\begin{array}{l}\text { Confined D. } \\
\text { Dynamic }\end{array}$ & $*$ & & $*$ & & & & $*$ & & & $*$ & & & & $*$ & $*$ & $*$ \\
\hline & Confined D. & $*$ & & $*$ & & $*$ & & $* *$ & & & $*$ & & & & $*$ & $*$ & $*$ \\
\hline$\sigma_{\mathrm{u}}$ & $\begin{array}{l}\text { Dynamic } \\
\text { Confined D. }\end{array}$ & $* * * *$ & & $* * * *$ & $*(\mathrm{AO})$ & $* * *$ & $* * *$ & & $* * *$ & & $* * * *$ & $* * * *$ & $* *$ & & $* * *$ & $* * * *$ & $* * * *$ \\
\hline
\end{tabular}

For significant correlation. Acronym description is provided in Table 1 . AO: correlation affected when removing the outliers. i.e. ${ }^{*} p<0.05$, ${ }^{* *} p<0.01,{ }^{* * *} p<0.001$.

Table 4

Comparison with literature (Follet et al., 2011; Mittra et al., 2005; Teo et al., 2006; Halgrin, 2009).

\begin{tabular}{|c|c|c|c|c|c|c|c|c|c|c|c|c|c|}
\hline \multirow[b]{3}{*}{ Reference } & \multicolumn{5}{|l|}{$E_{\text {app }}$} & \multicolumn{5}{|l|}{$\sigma_{\mathrm{u}}$} & \multicolumn{3}{|l|}{$\varepsilon_{\mathrm{u}}$} \\
\hline & \multicolumn{3}{|c|}{ Quasi-static (QS) } & \multicolumn{2}{|l|}{ Dynamic } & \multicolumn{3}{|c|}{ Quasi-static (QS) } & \multicolumn{2}{|l|}{ Dynamic } & \multirow{2}{*}{$\begin{array}{l}\text { QS } \\
\begin{array}{l}\text { Teo et al. } \\
(2006)\end{array}\end{array}$} & \multicolumn{2}{|l|}{ Dynamic } \\
\hline & $\begin{array}{l}\text { Follet et al. } \\
\text { (2011) }\end{array}$ & $\begin{array}{l}\text { Mittra et al. } \\
(2005)\end{array}$ & $\begin{array}{l}\text { Teo et al. } \\
(2006)\end{array}$ & $\begin{array}{l}\text { Halgrin } \\
(2009)\end{array}$ & Study & $\begin{array}{l}\text { Follet et al. } \\
\text { (2011) }\end{array}$ & $\begin{array}{l}\text { Mittra et al. } \\
(2005)\end{array}$ & $\begin{array}{l}\text { Teo et al. } \\
(2006)\end{array}$ & $\begin{array}{l}\text { Halgrin } \\
(2009)\end{array}$ & Study & & $\begin{array}{l}\text { Halgrin } \\
(2009)\end{array}$ & Study \\
\hline $\mathrm{BV} / \mathrm{TV}$ & * & $*$ & $*$ & $*$ & * & $*$ & * & $*$ & * & * & NC & $*$ & $\mathrm{NC}$ \\
\hline Tb.Th & * & $*$ & * & * & $*$ & $*$ & * & * & * & NC & NC & * & $\mathrm{NC}$ \\
\hline Tb.Sp & $*$ & $*$ & $*$ & * & $*$ & $*$ & * & $*$ & $\mathrm{NC}$ & $*$ & $\mathrm{NC}$ & $\mathrm{NC}$ & $\mathrm{NC}$ \\
\hline Conn.D & & $\mathrm{NC}$ & & & $\mathrm{NC}$ & & * & & & * & & & $\mathrm{NC}$ \\
\hline FD & * & & & * & $*$ & * & & & * & * & & $\mathrm{NC}$ & $\mathrm{NC}$ \\
\hline SMI & & * & * & * & NC & & * & * & $*$ & $*$ & NC & $\mathrm{NC}$ & $\mathrm{NC}$ \\
\hline DA & & $\mathrm{NC}$ & $\mathrm{NC}$ & $\mathrm{NC}$ & $\mathrm{NC}$ & & * & * & $\mathrm{NC}$ & $\mathrm{NC}$ & $\mathrm{NC}$ & $\mathrm{NC}$ & $\mathrm{NC}$ \\
\hline MIL1 & * & & & * & * & * & & & * & * & & $*$ & $\mathrm{NC}$ \\
\hline MIL2 & * & & & * & * & * & & & * & * & & $\mathrm{NC}$ & $\mathrm{NC}$ \\
\hline MIL3 & $*$ & & & * & * & $*$ & & & $*$ & $*$ & & $\mathrm{NC}$ & $\mathrm{NC}$ \\
\hline
\end{tabular}

*For significant correlation. NC: no correlation. Not colored box=correlation not studied.

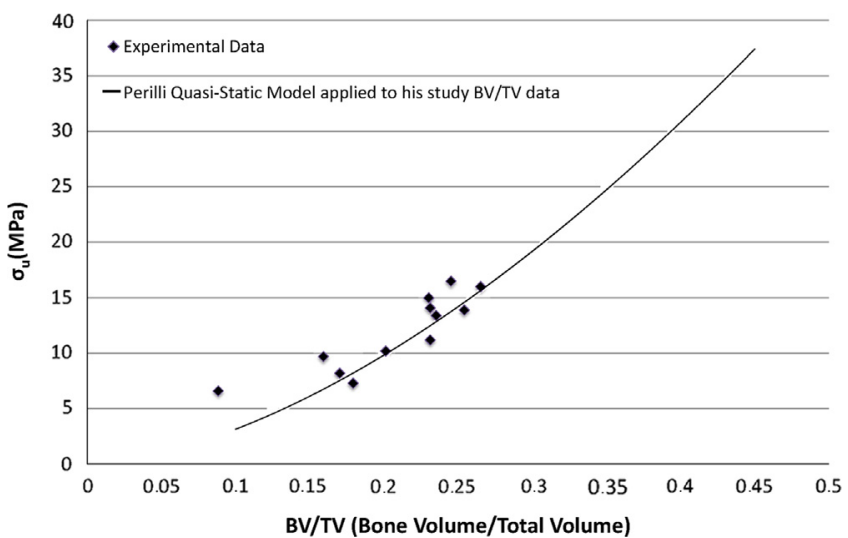

Fig. 6. Regressions for correlated parameters BV/TV and ultimate stress and the law of Perilli et al. 2007.

Correlations observed for dynamic compression loading were mainly found to be relevant in comparison with Halgrin's Ph.D. work (Halgrin, 2009) except the correlation between $\varepsilon_{\mathrm{u}}$ and both $\mathrm{BV} / \mathrm{TV}, \mathrm{Tb} . \mathrm{Th}$, that does not appear in the present study. Differences observed can be explained by the provenance (femur versus rib), the geometry of the specimen (cylinder versus square) especially under dynamic loading (Dong et al., 2004), and the fact that $\varepsilon_{\mathrm{u}}$ determination is operator dependent.

\subsection{Comparison between dynamic and confined dynamic loading}

It is well known that bone marrow influences the cancellous bone response at low strain rate (Linde and Hvid, 1989). Our comments on the comparison between the two different strain rates highlight the potential of predicting cancellous bone response. The authors regret not having any published study to compare their correlation under dynamic confinement to lower strain rate confined ones. A comparison can however be made between the two boundary conditions at high strain rate.

Different strain rates were used for dynamic and confined dynamic loadings ( $1000 \mathrm{~s}^{-1}$ and $1500 \mathrm{~s}^{-1}$ respectively) as data from non-confined tests at $1500 \mathrm{~s}^{-1}$ were not sufficiently wellconditioned to analyze, while confined tests at $1000 \mathrm{~s}^{-1}$ did not crush the bone. Hence, a compromise was made to develop a comparison with the hypothesis in same range.

Under confined dynamic loading, no significant correlation was found with $\sigma_{\mathrm{u}} \cdot \varepsilon_{\mathrm{u}}$ presented correlations with regard to architectural parameters that standard dynamic ones did not highlight. To explain this result, an additional study of the correlation with mechanical response of confined cancellous bone under low strain rate loadings could provide understanding of this correlation.

Architecture appears to be a good predictor of confined dynamic $\varepsilon_{\mathrm{u}}$ and, under non-confined loading, a good predictor of $\sigma_{\mathrm{u}}$ completed with $W_{\mathrm{u}}$. There is more information for confined dynamic loading which is more realistic in terms of the boundary condition made by the cortical bone around the cancellous bone, containing the bone marrow even if this experiment is an idealization of the interaction between the two bone materials. As the cell is stiffer than cancellous bone, a slight difference might be observed; it would be interesting to overcome the difficulty of realizing experiments in real confinement of cancellous bone in a cortical bone layer as made at low strain rate.

This study confirmed that confined dynamic loading can then be predicted for the case of elasticity up to fracture of trabeculae. By studying the plateau stress characteristic of a porous medium (Evans et al., 1998), the study may be extended up to the densification of broken trabeculae.

In conclusion, the compression tests were performed using two different boundary conditions (confined and non-confined). This work presents a new approach to cancellous bone mechanical prediction under dynamic loading via architectural parameters description. The relative usefulness of architectural parameters (geometry and 
morphology, topology, connectivity, and anisotropy) has been highlighted with regard to the prediction of elasticity up to fracture. As persistent links have been made between the different loadings, our data suggest that a realistic model (i.e., confined bone) based on the imaging acquisition method (i.e., architectural description) can be built for the prediction of daily risks (i.e., quasi-static loading) or rupture mechanism in the case of a known magnitude trauma (i.e., dynamic loading for car crash accidents).

\section{Conflict of interest statement}

None declared.

\section{Acknowledgments}

The authors wish to thank B. Mokhtari for providing the knowledge necessary to proceed with Java programming. The authors are also indebted to the Hôpital Lariboisière for imaging and to LMTCachan laboratory for providing access to testing equipment.

\section{References}

Boruah, S., Henderson, K., Subit, D., Salzar, R., Shender, B., Paskoff, G. 2013. Response of human skull bone to dynamic compressive loading. In: Proceedings of the IRCOBI Conference.

Bouxsein, M.L., Boyd, S.K., Christiansen, B.A., Guldberg, R.E., Jepsen, K.J., Müller, R., 2010. Guidelines for assessment of bone microstructure in rodents using micro-computed tomography. J. Bone Miner. Res. 25 (7), 1468-1486.

Chaary, F., Markiewicz, E., Drazetic, P., 2007. Identification of the spongy bone mechanical behavior under compression loads: numerical simulation versus experimental results. Int. J. Crashworth. 12 (3), 247-253.

Charlebois, M., Haunschmid, C., Zysset, P., 2008. Confined and unconfined compression tests of human trabecular bone up to very large strains. J. Biomech. 41 (S1).

Dong, X., Yeni, Y., Les, C., Fyhrie, D., 2004. J. Biomed. Mater. Res. Part A 68 (3), $573-583$.

Doube, M., Kosowski, M.M., Arganda-Carreras, I., Cordelieres, F., Dougherty, R.P. Jackson, J., Schmid, B., Hutchinson, J.R., Shefelbine, S.J., 2010. Free and extensible bone image analysis in Image. Bone 47, 1076-1079.

Evans, A.G., Hutchinson, J.W., Ashby, M.F., 1998. Multifunctionality of cellular meta systems. Prog. Mater. Sci. 43 (3), 171-221.

Follet, H., Bruyre-Garnier, K., Peyrin, F., Roux, J.P., Arlot, M.E., Burt-Pichat, B., Meunier, P.J., 2005. Relationship between compressive properties of human os calcis cancellous bone and microarchitecture assessed from $2 \mathrm{D}$ and $3 \mathrm{D}$ synchrotron microtomography. Bone 36 (2), 340-351.

Follet, H., Viguet-Carrin, S., Burt-Pichat, B., Depalle, B., Bala, Y., Gineyts, E., Bouxsein, M.L., 2011. Effects of preexisting microdamage, collagen cross-links, degree of mineralization, age, and architecture on compressive mechanical properties of elderly human vertebral trabecular bone. J. Orthop. Res. 29.4, 481-488.
Garrison, J., Gargac, J., Niebur, G., 2011. Shear strength and toughness of trabecular bone are more sensitive to density than damage. J. Biomech 4416, 2747-2754.

Gary, G. David Manual, 2005. Available from:〈http://www.lms.polytechnique.fr/ dynamique/greef/web4034 david.html〉.

Genant, H.K., Engelke, K., Fuerst, T., Gluer, C.C., Grampp, S., Harris, S.T., Jergas, M., Lang, T., Lu, Y., Majumdar, S., 1996. Noninvasive assessment of bone mineral and structure: state of the art. J. Bone Miner. Res. 11.6, 707-730.

Guedes, R.M., Simoes, J.A., Morais, J.L., 2006. Viscoelastic behaviour and failure of bovine cancellous bone under constant strain rate. J. Biomech. 39.1, 49-60.

Halgrin, J., 2009. Influence Des Paramètres Architecturaux Sur le Comportement Mécanique de L'os Trabéculaire (Ph.D. thesis). Université Lille Nord-de-France. Available from: 〈http://tel.archives-ouvertes.fr/tel-00494612/〉.

Halgrin, J., Chaari, F., Markiewicz, E., 2012. On the effect of marrow in the mechanical behavior and crush response of trabecular bone. J. Mech. Behav. Biomed. Mater. 5.1, 231-237.

Higgins, S., 2008. Strain Rate and Density Dependent Behaviour of Bovine Cancellous Bone in Compression. (MSc. thesis). University of Cape Town.

Laporte, S., David, F., Bousson, V., Pattofatto, S., 2009. Dynamic behavior and microstructural properties of cancellous bone. In: Proceedings of the DYMAT, pp. 895-900.

Linde, F., Hvid, I., 1989. The effect of constraint on the mechanical behaviour of trabecular bone specimens. J. Biomech. 22 (5), 485-490.

Linde, F., Nørgaard, P., Hvid, I., Odgaard, A., Sballe, K., 1991. Mechanical properties of trabecular bone: dependency on strain rate. J. Biomech. 24 (9), 803-809.

Linde, F., Hvid, I., Madsen, F., 1992. The effect of specimen geometry on the mechanical behaviour of trabecular bone specimens. J. Biomech. 25 (4), 359-368.

Linde, F., Sørensen, H., 1993. The effect of different storage methods on the mechanical properties of trabecular bone. J. Biomech. 26.10, 1249-1252.

Liu, J., Saletti, D., Pattofatto, S., Zhao, H., 2014. Impact testing of polymeric foam using Hopkinson bars and digital image analysis. Polym, Test. 36, 101-109.

Mitton, D., Rumelhart, C., Hans, D., Meunier, P.J., 1997. The effects of density and test conditions on measured compression and shear strength of cancellous bone from the lumbar vertebrae of ewes. Med. Eng. Phys. 19.5, 464-474.

Mittra, E., Rubin, C., Oin, Y.X., 2005. Interrelationship of trabecular mechanical and microstructural properties in sheep trabecular bone. J. Biomech. 38.6, 1229-1237.

Morgan, E.F., Keaveny, T.M., 2001. Dependence of yield strain of human trabecular bone on anatomic site. J. Biomech. 34.5, 569-577.

Nazarian, A., Araiza Arroyo, F., Rosso, C., Aran, S., Snyder, B., 2011. Tensile properties of rat femoral bone as functions of bone volume fraction, apparent density and volumetric bone mineral density. J. Biomech. 44.13, 2482-2488.

Perilli, E., Baleani, M., Ohman, C., Fognani, R., Baruffaldi, F., Viceconti, M., 2007. Dependence of mechanical compressive strength on local variations in microarchitecture in cancellous bone of proximal human femur. J. Biomech. 41, 438-446.

Syahrom, A., 2011. Mechanical and Micro-architectural Analyses of Cancellous Bone Through Experiment and Computer Simulation. IFMBE.

Teo, J., Si-Hoe, K.M., Keh, J.E.L., Teoh, S.H., 2006. Relationship between CT-intensity, micro-architecture and mechanical properties of porcine vertebral cancellous bone. Clin. Biomech. 21.3, 235-244.

Van Rietbergen, B., Weinans, H., Huiskes, R., Odgaard, A., 1995. A new method to determine trabecular bone elastic properties and loading using micromechanical finite-element models. J. Biomech. 28 (1), 69-81.

Yeni, Y.N., Zinno, M.J., Yerramshetty, J.S., Zauel, R., Fyhrie, D.P., 2011. Variability of trabecular microstructure is age, gender, race and anatomic site dependent and affects stiffness and stress distribution properties of human vertebral cancellous bone. Bone 49.4, 886-889.

Zhou, B., Sherry Liu, X., Wang, J., Lucas Lu, X., Fields, A.J., Edward Guo, X., 2014. Dependence of mechanical properties of trabecular bone on plate-rod microstructure determined by individual trabecula segmentation (ITS). J. Biomech. $47.3,702-708$. 